\title{
Entry into a Global Industry of Proprietary Technological Systems -- Criticality of Defense Conversion and Systems Architecture
}

\author{
Jong-Tsong Chiang \\ College of Management \\ National Taiwan University \\ 50, Lane 144, Section 4, Keelung Road \\ Taipei, Taiwan, R.O.C.
}

\begin{abstract}
Taiwan's government has officially targeted the commercial aircraft industry and the main force is a combat aircraft producer. However, the prospect of defense conversion is dismal because neither spin-off nor dual-use strategy can apply effectively. Moreover, the integral architecture of the systems products constitutes an insurmountable barrier, leading to a prediction of the futility of this national move.
\end{abstract}

\section{TRANSFORMATION OF A NATIONAL CHAMPION}

\section{A. Seeking Entry into the Aircraft Industry}

The industry of large commercial jet aircraft is a typical global industry characterized by high capital investment and $R \& D$ costs, lengthy development and production cycles, and volatile markets of airlines' orders affected now by a variety of financial and political factors. ${ }^{\mathrm{l}}$ This industry has the structure of a pyramid. At the first tier, a few airframe and engine integrators constitute two oligopolistic groups. They virtually dominate systems design, manufacturing, and sales, manage the vast network of suppliers and subcontractors, and provide customer support for the 20 to 30 years of the product life. In a relative sense, most other prime manufacturers of general aviation and even military aircraft and the suppliers of structure, equipment, components, and parts are small businesses. Aero Industry Development Center (AIDC) - the producer of Taiwan's military aircraft with a history of two and a half decades - is no exception.

Because the aircraft industry is a user and driver of advanced product and process technologies, in 1990 Taiwan's government officially targeted this industry as a strategic field receiving policy support and financial endorsement. ${ }^{2}$ In 1996 AIDC was transformed from a military organization directed by the Ministry of National Defense into a government-owned corporation supervised by the Ministry of Economic Affairs. And so this defense champion became also a commercial champion expected to lead the commercial aircraft industry nearly nonexistent in Taiwan ${ }^{3}$ - into a new era. This paper,

\footnotetext{
${ }^{1}$ For the severe political and financial environment of the commercial aircraft industry beginning in the 1980s, see Dertouzos et al. (1989), pp. 210-216.

In 1991, a commercial company, Taiwan Aerospace Co., was launched under the government's auspices. But this company has so far never played any substantive role and thus been commonly regarded as a failure.
}

${ }^{3}$ Data from different sources about the industry production value range, for without giving militarily important information and technical details (except those already open to the public through mass media), tries to identify and explain the structural challenges AIDC in particular and Taiwan in general will be facing in this endeavor of entry into the commercial aircraft industry.

\section{B. Establishment of a Combat Aircraft Industry}

In a follower country, usually the domestic capabilities for a military system evolve in the following sequence: maintenance and repair, licensed production and modification, independent production of subsystems, and finally indigenous design, development, and production of the whole system (normally still needing the supply of critical parts and subsystems from advanced countries). In parallel, the evolution also proceeds in the direction of making more sophisticated weapons systems. ${ }^{4}$ The production of military aircraft in many newly industrialized countries seems to have roughly followed this path. Constrained by limited resources and capabilities, most countries relied heavily on licensed technology and concentrated on trainers or fighters - the types of aircraft most related to their direct defense needs. ${ }^{5}$

In Taiwan, due to deep concern about national security and international political isolation that may cause supply interruption, AIDC for the past decades has been strictly defense-oriented without consideration of the commercial sector. Around 1970 AIDC retrofitted twenty or so U.S. T28 trainers and replaced their piston engines with turboprop engines. This was AIDC's first major program. Its another major action was under Northrop's strong technical support and sixty AT-3 twin-engine jet trainers were produced in the early 1980s. After then AIDC worked on the development of new-generation combat aircraft - the Indigenous Defense Fighters (IDFs). The normal production began in 1992.

In the IDF program, the dependence on foreign suppliers could hardly be reduced. Aerodynamics and systems design were assisted by General Dynamics, whose product F-16 was emulated. And nearly all the avionics and structural materials were also from the U.S. Concerning power plant, because high-power jet engines could not be procured, Taiwan financed Garrett to upgrade its original design of 3750-pound thrust to a new model of 4500-pound thrust, and

\section{example, from US\$0.4 million to 18 million in 1994}

${ }^{4}$ For the defense industry in developing countries, see Wulf (1983).

SFor the establishment of the military aircraft industry in newly industrialized countries, see Tood and Simpson (1986), pp. 177-180. 
AIDC and Garrett jointly produced the engines solely for IDFs. In this way, one IDF equipped with two engines (including after-burners of additional 1000-pound thrust each) could roughly match one F-16 in thrust power. According to the official plan, by the end of this century Taiwan's Air Force will have had 130 IDFs (as well as 150 F-16s and 60 Mirage 2000-5s).

By now AIDC employs about 5000 people, one third in $R \& D$ and the remainder in the production of aircraft, engines, and other equipment. In terms of technological capabilities, AIDC is relatively strong in applying wind tunnels for aerodynamic analysis, assembling engines and airframes, and manufacturing airframe structure and limited parts of engines, but especially weak in avionics. In terms of production costs, local suppliers and subcontractors (mostly for tooling and machining) account for only one tenth of AIDC's total local business. Because of its technical talent in depth and multidisciplinary teams, AIDC excels in taking on large-scale projects of systems engineering and is regarded by some people as national treasures worth preserving.

\section{Two Main Challenges}

In Taiwan, the reorientation of AIDC represents the historically first endeavor in defense conversion. It is expected that AIDC currently pursuing military missions could be more responsive and useful to the civilian sector. In fact, as the defense task fades, especially after the completion of the IDF program around 2000 , other commercial missions should replenish the well, or else AIDC has to shrink drastically.

However, AIDC's plan of entry into the commercial aircraft industry is considered by the government as implementing the so-called spin-off strategy with the advantage of a legacy of physical facilities and human talents in engineering and project management. This may be assumed mistakenly and thus requires further elaboration.

Another main challenge pertains to the characteristics of the aircraft industry. This industry exemplifies one of the most complex high-tech fields of systems engineering. Even the Japanese, with their profound technological foundation in materials processing, electronics, and computers, have not yet become an independent force in commercial aviation. Indeed, their capabilities in both airframes and engines have grown enormously during the past decades. They are still quite far from having the requisite infrastructure. In this view, it is not plainly justifiable for Taiwan's government to target commercial aircraft.

Next section will deal with the first challenge of defense conversion and begin with the discussion of spin-off.

\section{DEFENSE CONVERSION}

\section{A. Mission-Oriented Programs and Conversion}

Spin-off is the spill-over from mission-oriented programs. These programs are guided by specific missions defined by mission agencies, typified by the defense ministry (as well as the aerospace agency), whose operational responsibilities mandate immediate operating goals and put the agencies under constant pressure to produce results. Therefore, mission agencies are the primary end users of the outcomes of their mission-oriented programs. And technical activities and other investments endorsed or undertaken by these agencies normally pertain to their missions and, more specifically, their procurement interests. As a result, spin-off is basically serendipitous because it falls beyond the scope of these programs' main missions and is not planned deliberately beforehand.

Because many mission programs account for a large amount of national resources, it is often expected that these programs, in addition to accomplishing the designated missions, can also contribute to the civilian sector. In this regard, spin-off may take many forms. It may provide employment, boost some industries, strengthen infrastructure, and benefit civilian technology development. In the high-tech arena, technological spin-off is of crucial importance. However, military technology can hardly be translated into commercial success automatically, because the former primarily pursues product performance improvements at the expense of cost efficiency. Therefore the conversion process to attain economic viability defined by the civilian market, which is different from the government market, could be very complex, time-consuming, and costly. ${ }^{b}$

To circumvent the spin-off difficulties, the dual-use strategy - meaning that the investment is from the very beginning planned for both military and commercial applications - may sound plausible. In practice, however, most applicationoriented technical work sponsored by government agencies (and by private companies as well) is not intentionally multiuse, even if some degree of dual-use potential is inherent in many technologies. For pragmatic reasons, dual use is rarely the first priority of any government mission agency (or of any private commercial firm).

It could be argued further that some mission agencies may also endorse upstream and fundamental research that may have more dual-use potential. But this also implies that the applications are more indirect and more distant from the present research stage. In consideration of the total investment needed, the contribution of the dual-use potential in this early stage to the whole process of innovation very probably represents only a very small fraction.?

\section{B. Dual-Use Potential and Spin-Off Mechanisms}

Despite the main issues as discussed formerly, some general guidelines could be followed to promote spin-off and dual use. First of all, it is reasonable to hypothesize that spin-off would be more intense, the more similar the military and civilian technologies, or the more closely interactive the concerned military and civilian communities, all other factors being equal. (In fact, the two conditions are very likely to be positively correlated.) Therefore, spin-off may be facilitated through such mechanisms as personal contact, R\&D cooperation, technical consultation, technology demonstration, technical data provision, publications, conferences, and the mobility of personnel from missionoriented programs to civilian industry. It also follows that spin-off would be easier the more civilian industry's involvement in military programs.

Additionally, even if the military weapons systems are highly specialized and distinctly different from the civilian products, and the first-tier prime contractors are restricted in

\footnotetext{
bSee Office of Technology Assessment (1993) especially for the case of U.S. Energy Department.

${ }^{7}$ For a thorough discussion of spin-off and dual-use strategy, see Alic et al (1992).
} 
the communication of classified information, more dual-use properties may exist in subsystems, parts, components, materials, instruments, tools, capital equipment and technical services, and the vast number of lower-tier subcontractors and suppliers working for these businesses may not be so subject to strict security regulations. Technology sharing and transfer at these tiers may therefore have more common grounds and less obstacles. And many of the products, processes, and services are purchased commercially. ${ }^{\circ}$

Besides the general rules, the U.S. magnificent spin-off history in computers, semiconductors, nuclear power, aircraft, and jet engines indicates that there are three crucial mechanisms worth noting. The first mechanism is the mission agencies' substantial R\&D contracts, subsidies, and collaboration in critical technologies of potential commercial relevance, without which civilian industry may underinvest because of the perceived unaffordably high risk or costs. The second mechanism is the agencies' assured procurement of new and expensive products, which creates the initial markets. The third mechanism is the agencies' promotion of technology diffusion and industry competition, which expands the industrial base and enhances the industrial metabolism. Through these three mechanisms, the industrial firms and research organizations upgrade their technical capabilities, acquire product design and production experience, and drive down costs. Commercial applications, in the form of improved or new products and processes, new industries, or reinforced infrastructure, then thrive. ${ }^{7}$

\section{Feasibility of Civil-Military Integration}

For all the general understanding as mentioned above, several practical questions should be raised about every real case, like AIDC, in defense conversion. First, what does AIDC have to offer, beyond its traditional work in military aircraft, that is truly valuable to civilian industry and national competitiveness? Second, assuming AIDC has outstanding capacities in technologies of importance to civilian industry, how readily available are these capacities? Can AIDC as a government-owned corporation work with private companies without serious delays or red tape? Finally, assuming private companies can get reasonable access to AIDC's valuable capacities, how do these partnerships fit into a national strategy and a broader scheme that will enhance the competitiveness of local industry? In fact, these questions also concern a broader inquiry about the potential and feasibility of the dual-use strategy or the integration of the defense and commercial industrial bases - often termed civilmilitary integration and meaning that common technologies, processes, labor, equipment, material, and/or facilities are used to meet both defense and commercial needs

Prudential answers to the above questions are not easy, and some can come only as the fruit of several years' experience. Confined to AIDC's plan targeting commercial aircraft, the following discussion tries to explore some tentative answers.

\section{NATIONAL CAPABILITIES}

\section{A. Industrial and Technological Profile}

${ }^{8}$ For a comprehensive study of integrating military and civilian technological bases, see Office of Technology Assessment (1994).

${ }^{9}$ For these three technological spin-off mechanisms, see Chiang (1992).
When the general profile of technological capabilities is considered, Taiwan as a newly industrialized economy belongs to the so-called late industrializer group (as opposed to the early industrializers, such as Britain, France, Germany, the U.S. and recently Japan). This group is characterized by such specific traits as recent modernization, low international competitiveness of the capital goods industries and a weak foundation in the related support services, and fairly high dependence on generic technologies and product standards developed in the U.S., Japan and Western Europe. ${ }^{30}$

Although Taiwan also has a competitive advantage in a few technology-intensive fields, such as semiconductor manufacturing, on the whole its indigenous expertise is still weak. If a recently proposed conceptual model of four stages of national development -- factor-driven, investment-driven, innovation-driven, and wealth-driven - is used, Taiwan's economy in general has not yet entered the innovation-driven stage. ${ }^{11}$ Leading firms can adopt an effective imitative strategy ${ }^{\mathrm{le}}$ - quickly following the world leaders in noncomplex technologies and relying mainly on cost advantage and flexibility. But they still depend on many foreign-made key components, not to speak of high-tech process equipment. Lack of technologically sophisticated user-supplier links within its national boundaries also confines Taiwan's firms to production of more standardized products, for which such links are not critical. An illustrative case is the information technology industry, exemplified by personal computers. ${ }^{2.3}$

\section{B. Segregation of Defense and Commercial Bases}

In this national context, the feat of AIDC was indeed achieved very "artificially" by the government through longterm commitment of huge resources under the military command system. However, this strategy can at best be used to deal with a small sector of the economy. The implications are two-fold.

First, not any of the three critical spin-off mechanisms R\&D cooperation, government procurement, and technology diffusion - could be really utilized to incubate an industrial base outside AIDC, because there are few qualified counterparts in the civilian sector. Second, in order to pursue self-reliance in defense, AIDC had to concentrate its very limited technological resources on the final systems products and outsource a very large proportion of subsystems, parts, components, materials, and equipment from abroad, if available. (In reality, the tasks related to aerodynamics and the interfaces among many subsystems for a combat aircraft are extremely complex and difficult and already represent a very great challenge to AIDC.) This has led to slow progress of indigenous capabilities below the systems level and also

\footnotetext{
10For the characteristics of late industrializers, see Ernst and O'Connor (1989), pp. 33-75.

12This conceptual model was proposed by Porter (1990), pp. 543-573.

12 For the requirements of six innovative strategies - offensive, defensive, imitative, dependent, traditional, and opportunistic, see Freeman (1982), pp. 169-186.

${ }^{13}$ For a brief discussion of Taiwan's general technological capabilities, see Chiang (1996), pp. 122-126. For the national systems supporting industrial technical advance, see Hou and Gee (1993).
} 
largely reduced the potential opportunities of dual-use technology sharing with local industry.

Actually, another serious issue is the insufficient economic incentives for civilian industry because of small orders and uneven production runs. Therefore even the offset programs organized by the government to urge foreign suppliers to transfer technology are not really attractive to local firms. As a result, AIDC is like an isolated enclave and virtually represents the whole aircraft industry in Taiwan. Though not discussed in this paper, the programs of guided missiles have faced similar difficulties. The military institutions have to do nearly all the development and production tasks and the involvement of local industry is minimal. Therefore, in hightech fields little civil-military integration exists because of the dual structure or segregation of the defense and commercial technology and industrial bases. This is in striking contrast with some other countries' experience. For example, military spending has sometimes been described as the U.S.'s de facto technology and industrial policy, albeit probably an unfocused and expensive way of advancing important commercial technologies.

If four broad attributes of Taiwan - factor conditions, demand conditions, supporting industries, and firm strategy, structure, and rivalry ${ }^{14}$ - that shape the environment for AIDC are examined, AIDC apparently has the following disadvantages: first, the very limited domestic base of human resources and infrastructure in this industry; second, the absence of supplier and related industries that are internationally competitive; third, the lack of home demand for the commercial products and thus the existence of twoedged direct pressures on AIDC to compete globally; and fourth, little acquaintance with global commercial practices and inexperience in integrating the military and civilian sides of business.

In fact, the aircraft business differs structurally from the types of industries the people in Taiwan have preferred to target. The case of AIDC may eventually typify a government's futile efforts, which are entirely distinct from the normal industrial practices in a free enterprise economy. Next section will discuss the contrast by investigating the characteristics of some representative industries and products - the second major challenge as has been pointed out formerly in the first section of this paper.

\section{SYSTEMS ARCHITECTURE}

\section{A. Industrial Modularity and Disintegration}

In the fields of electronics and information technology, Taiwan's firms have so far been performing rather satisfactorily. This has much to do with the modular architecture $^{15}$ of the products manufactured. The personal computer industry can provide some insightful lessons.

This industry is basically a highly open and modularized system with many internationally standardized components and easily adjustable interfaces. Even proprietary CPUs and memory chips could be purchased from merchant firms.

\footnotetext{
24These four determinants of national competitive advantage were the main theme of Porter (1990).

${ }^{25}$ For a seminal work on product architecture, modular and integral, see Ulrich (1995). For the innovations at the modular and architectural levels, see Henderson (1990).
}

Therefore, local firms could quite easily enter this industry by assembling final products and subsystems (e.g., key boards, monitors, chipsets, interface cards, and mother boards) based on OEM and ODM terms, and then by making key components and materials (e.g., liquid crystal displays, memory and logic chips, and silicon wafers).

The same rationale could explain Taiwan's success as an important supplier of many auto parts standardized within single world leaders or across multiple firms. In all these cases, firms with strong (and flexible) manufacturing competence can pursue their own scale economies and learning effects rather independently and in parallel through large production volumes. This is a very important "natural" rule underlying the rapid growth of many industries in Taiwan.

As a matter of fact, the semiconductor industry in Taiwan has followed a similar path and developed a quite unique industrial structure characterized by the independent operation of foundries. While in other countries the manufacturing capacities are almost entirely owned by large integrated firms, Taiwan's foundries do commercial transactions with external design houses or units by providing design rules and transistor models and receiving mask layouts for fabrication. This disintegration of the traditionally integrated business has helped establish a prosperous domestic sector of semiconductor design houses.

Briefly speaking, modularization as well as disintegration in effect reduces the product complexity, lowers the business entry barriers, and increases the industrial flexibility. ${ }^{\mathrm{lb}}$ It seems evident that Taiwan's businessmen as a group are distinctively good at this strategy. It is no wonder that they, with relatively small enterprises as main forces, survive the global competition in a way not commonly found in most other countries.

\section{B. Integral Product Architecture}

The aircraft industry is characteristically different from what Taiwan's industrialists are familiar with. Besides the high-tech capabilities needed for entry into this industry, the highly integral, not modular, architecture of the products constitutes another critical barrier.

Technology for modern aircraft and jet engines is extremely demanding because of the very high level of functional performance, reliability, safety, availability, and efficiency required and targeted at the systems level. In order for the overall system to work correctly, many subsystems and components should contribute in an integral way, meaning that many performance characteristics should arise from the properties of many parts of the product. This drives the design of product architecture to include complex systems of mapping from functional elements to physical components and of interfacing mechanisms between parts. Many part designers should interact continually for the integrative performance of the upper-level systems to which their parts belong. They should also manage changes frequently because the changes of other parts, even not within their responsibility, may call for modifications of their parts. Tight coordination of design and integration tasks is thus essential to the success of the whole system. This leads to the dominant position of the systems builders.

\footnotetext{
16For a more detailed discussion about modularity, see Kogut and Bowman (1995).
} 
More specifically, in the aircraft industry there exist two groups led respectively by the airframe integrators and the engine manufacturers. The reasons are two-fold. On the one hand, the modern jet engine is a very strict integral architecture with very high entry barrier and its technological foundation is entirely different from that of the airframe. On the other hand, although the engine is in complex interaction with aerostructure and aerodynamics of the whole system, the related technology for systems integration basically falls within the airframe integrators' traditional core competence. Besides, without too many difficulties to overcome, two parties can cooperate on the interfacing mechanisms connecting the engine and the airframe (especially fuel supply and control systems). Therefore, few airframe builders have tried to integrate the engine business and most airframes are offered with a choice of engines. The engine makers design and produce their propulsion systems in close association with the airframe integrators, manage their own subcontracting systems, market their products both to the airframe builders and the airlines, and maintain their own customer-support networks.

Product architecture has profound managerial implications. As another representative case, it can be inferred that the government-sponsored program of developing a common engine for the auto industry would face serious problems. In fact Taiwan's national R\&D institutes have successfully developed the 5-C system (i.e., cylinder, cylinder head, cylinder piston, crankshaft, and camshaft). How to adapt this engine to different car models in a technically optimal way is really an insurmountable difficulty. On the one side, the heart of engine (i.e., the 5-C system) is a compact integral architecture difficult to change flexibly and, on the other side, each car maker has its own proprietary systems design. Because the engine interfaces with other subsystems (especially the transmission system) and fits into the systems architecture (e.g., size, shape, mass, and balance) in a very complex way, the conversion cost could be prohibitively high for the incumbent car makers to modify their systems architectures in order to adopt this common engine. Therefore that the common engine when viewed in isolation is superior to the engines currently used by car makers can by no means sufficiently justify this development program.

Based on the rationale discussed thus far, next section will briefly examine AIDC's potential in commercial business.

\section{BUSINESS POSITIONING}

\section{A. Systems Design and Integration}

In the market of military aircraft, because AIDC imported many critical subsystems and technologies from the U.S., AIDC could not export combat aircraft without the U.S. government's consent. Besides, while AIDC has focused its main efforts on the systems technology (i.e., aerodynamics, structure, and engines in particular), it still cannot define, develop and produce original products. In product support and logistics engineering, it takes time for AIDC to make track records.

In the commercial realm, international cooperation is a necessity if AIDC attempts to enter the systems business (like the segment of regional jets, as promulgated by the government). However, AIDC's capabilities in systems design and integration are so far confined to combat fighters. Many deeply rooted obstacles exist.

In aircraft design, many early commercial jets were similar to military transports and even bombers (excluding the recent B-1 and B-2 bombers) in geometry and streamlined shapes. Therefore spin-off was usually quite direct. Nevertheless, modern combat aircraft's technological requirements, including far higher priority on speed and maneuverability, are drastically different from civilian needs. ${ }^{17}$ In contrast, commercial aircraft mainly emphasize efficiency, environmental impact, safety, and comfort. In other words, military and civilian needs have become very different, which has greatly reduced the commercial benefits of military work on airframes in particular. Airframe companies, which design and assemble the final products, now have to fund most of their commercial development costs. (For jet engines, however, the gap between military and civilian technology is narrower, and so engine companies can recover a larger share of their $R \& D$ for military programs. ${ }^{18}$ ) Therefore, relative to any potential ally, AIDC does not have much value or leverage either in the development of new or derivative aircraft models or in the integrative assembly work..

\section{B. Contract Manufacturing}

Below the systems level, AIDC can do contract manufacturing. In this arena, a manufacturer's value mainly comes from efficiency, product design, and process knowhow. But AIDC is not yet a strong efficient competitor. First of all, AIDC's present production system as a whole is for combat aircraft, not appropriate for the OEM business. As to scale and scope economies, AIDC's production capacity is relatively small and its few projects are difficult to induce strong cross-fertilization effects. In the meantime, the limited production volume so far has not been able to drive AIDC quickly down the experience curve. In fact, AIDC's position has even been exacerbated by the recent participation of several low-cost competitors (i.e., Eastern Europe and the Mainland China) with overcapacity of production and considerable technological expertise at least in military aircraft

Furthermore, if AIDC succeeds in some niches (most probably in the fields of forging, casting, and machining), the top-down proprietary technological systems constitute another insurmountable barrier. In this industry of integral architecture, most functional and design specifications and standards are imposed by the upper-tier buyers or ultimately the integrators. In many cases, the process of manufacture is also defined from above because it is closely related to product requirements of very high performance. To be qualified for manufacturing, subcontractors must strive to get certifications from the respective integrators in the concerned products and processes first - without assurance of following orders. ${ }^{19}$ In a quite closed system of this kind, AIDC as a late entrant has little room for business maneuvering. This reduces the strategic value of being a contract manufacturer.

\section{IMPLICATIONS}

From the standpoint of military interests and requirements, civil-military integration is highly desirable. But can that be

\footnotetext{
1. ?For military aircraft technology, see Frostic (1989),

${ }^{28}$ For this situation in commercial aircraft design, see Dertouzos et al. (1989), p. 206.

${ }^{19}$ For the technological structure in the aircraft industry, see March (1989).
} 
achieved better by turning defense organizations into dualuse companies? From the standpoint of the nation's economic performance, a policy approach that offers transition assistance to defense companies struggling to survive in the commercial world while opening technology diffusion and development opportunities to all companies equally is also highly justifiable. But can that be implemented effectively and efficiently? The foregoing discussion, largely judgmental, suggests that answers to both questions in Taiwan are very probably negative. It is not yet pragmatic to think of using dual-use strategy or civil-military integration to further economic development.

In fact, the defense and commercial sectors each have different game rules or industrial practices. In national defense, many mission-oriented establishments are indispensable. If a small follower country like Taiwan seeks to produce high-tech weapons systems that can match some items in advanced countries, it must first concentrate its very limited resources on the final systems products. Then the reorientation of these devoted resources to commercial purposes will be very "lonely" and difficult, because the dual-use potential is minimal, the spin-off mechanisms are not easy to work, the capability gap between the military and civilian sectors is much wider than that in a larger advanced country like the U.S., and the new commercial business may even fall under the world leading integrators' dominance through their proprietary technological systems.

In the case of the aircraft industry, Taiwan's government has extended its financial arms for international joint venture, risk sharing, licensing, and coproduction. But these means are only like entry fees. Serious structural problems are many, including how AIDC can substantially reengineer, upgrade, and sustain its capabilities and how Taiwan's firms can effectively enhance their relative position in the architecture of the aircraft industry.

As a preliminary conclusion, Taiwan's experience exemplified by the transformation of AIDC suggests that, while the military driving force may be useful to mobilize resources to carry out mission-oriented programs, the prospect of defense conversion into commercial business is dismal. Actually, Taiwan's struggle also reveals the very difficulty of having a strong hold in an industry of high-tech integral architecture. The challenge centers on both strategic positioning and core competence, demanding that a player be able to occupy a critical node in the value chain or network and provide kernel products that have at least an equal position to match other complementary parts or modules, to fit in upper-tier architectures, and to incorporate lower-tier components. In light of the lessons gained, Taiwan's idiosyncratic experience in the aircraft industry seems to have general implications for many other countries to elaborate.

\section{REFERENCES}

Alic, John A., Lewis M. Branscomb, Harvey Brooks, Ashton B. Carter and Gerald L. Epstein (1992), Beyond Spinoff, Boston, MA: Harvard Business School Press.

Chiang, Jong-Tsong (1992), "Technological Spin-Off: Its Mechanisms and National Contexts," Technological Forecasting and Social Change, Vol. 41 , pp. $365-390$

Chiang, Jong-Tsong (1996), "Development of Technology Management in Taiwan," in Karen Minden and Wong Poh-Kam (eds.), Developing Technology Managers in the Pacific Rim: Comparative Strategies, Armonk, NY: M.E. Sharpe.

Dertouzos, Michael L., Richard K. Lester, Robert M. Solow, and the MIT Commission on Industrial Productivity (1989), Made in America: Regaining the Productive Edge, Cambridge, MA: The MIT Press

Ernst, Dieter and David O'Connor (1989), Technology and Global Competition: The Challenge for Newly Industrializing Economies, Paris: OECD.

Freeman, Christopher (1982), The Economics of Industrial Innovation, Cambridge, MA: The MIT Press.

Frostic, Frederick L. (1989), "Technology and Air Forces," in Asa A. Clark, IV and John F. Lilley (eds.), Defense Technology, New York, NY: Praeger.

Henderson, Rebecca M. and Kim B. Clark (1990), "Architectural Innovation: The Reconfiguration of Existing Product Technology and the Failure of Established Firms," Administrative Science Quarterly, Vol. 35, pp. 9-30.

Hou, Chi-Ming and San Gee (1993), "National Systems Supporting Technical Advance in Industry: The Case of Taiwan," in Richard R. Nelson (ed.), National Innovation Systems, New York, NY: Oxford University Press.

Kogut, Bruce and Edward H. Bowman (1995), "Modularity and Permeability as Principles of Design," in Edward H. Bowman and Bruce Kogut (eds.), Designing the Firm, New York, NY: Oxford University Press.

March, Artemis (1989), "The US Commercial Aircraft Industry and its Foreign Competitors," in the MIT Commission on Industrial Productivity (ed.), The Working Papers of the MIT Commission on Industrial Productivity, Cambridge, MA: The MIT Press.

Office of Technology Assessment (1993), Defense Conversion: Redirecting $R \& D$, Washington, DC: Government Printing Office.

Office of Technology Assessment (1994), Assessing the Potential for CivilMilitary Integration: Technologies, Processes, and Practices, Washington, DC: Government Printing Office.

Porter, Michael E. (1990), The Competitive Advantage of Nations, New York, NY: The Free Press.

Tood, Daniel and Jamine Simpson (1986), The World Aircraft Industry, Dover, MA: Auburn House Publishing Co.

Ulrich, Karl (1995), "The Role of Product Architecture in the Manufacturing Firm," Research Policy, Vol. 24, pp. 419-440.

Wulf, Herbert (1983), "Developing Countries," in Nicole Ball and Milton Leitenberg (eds.), The Structure of the Defense Industry: An International Survey, New York, NY: St. Martin's Press. 